\title{
Effect of fine particles on strength and stiffness of cement treated sand
}

\author{
Sung-Woo Moon ${ }^{1} \cdot$ Ganapathiraman Vinoth ${ }^{2} \cdot$ Sathya Subramanian ${ }^{3} \cdot J^{\text {Jong }} \mathrm{Kim}^{1} \cdot$ Taeseo Ku$^{3} \odot$
}

Received: 7 June 2019 / Published online: 15 November 2019

(c) The Author(s) 2019

\begin{abstract}
Naturally available sands are always found with finer particles of varying sizes and proportions which are generally not accounted for in the geotechnical design of a cemented soil system. This paper explores the behavior of cemented sand with fine particles in smaller proportions. Two types of cements: (1) ordinary portland cement (OPC), (2) calcium sulfoaluminate cement (CSA); three cement contents: $3 \%, 5 \%, 7 \%$ and four fine (kaolin powder) contents: $0 \%, 1 \%, 3 \%, 5 \%$ are considered in this study. The ultrasonic pulse velocity (UPV), shear wave velocity $\left(V_{s}\right)$ and unconfined compressive strength (UCS) are measured to investigate the effects of fine particles on the cemented sand. The results show that fine particles do affect quite significantly the mechanical properties of cement-treated sand, even at negligent proportions. The strength and stiffness increase with fine content in both types of cement. The increase in strength and stiffness with increasing fine contents is attributed to the increased density with kaolin acting as a filler material facilitating more contact points among the particles. The results also show that the effect of fine particles on cemented sand depends not only on their relative volume and mineralogy but also on the type of the binding material.
\end{abstract}

Keywords Calcium sulfoaluminate $\cdot$ Cement-treated sand $\cdot$ Compressive strength $\cdot$ Fines content $\cdot$ Kaolin $\cdot$ Shear wave velocity

Sung-Woo Moon: formerly at National University of Singapore; Ganapathiraman Vinoth: formerly at National University of Singapore.

\section{Taeseo Ku}

ceekt@nus.edu.sg

Sung-Woo Moon

sung.moon@nu.edu.kz

Ganapathiraman Vinoth

gv1134@mail.ubc.ca

Sathya Subramanian

subramanian@u.nus.edu

Jong Kim

jong.kim@nu.edu.kz

1 Department of Civil and Environmental Engineering, Nazarbayev University, 53 Kabanbay Batyr Ave, 010000 Nur-Sultan, Kazakhstan

2 Department of Civil Engineering, The University of British Columbia, 6250 Applied Science Lane, Vancouver, BC V6T 1Z4, Canada

3 Department of Civil and Environmental Engineering, National University of Singapore, 1 Engineering Drive 2, Singapore 117576, Singapore

\section{Introduction}

Cement treatment of soils is one of the widely used ground improvement techniques [1]. The engineering properties of soils can be greatly improved, even at lower cement contents [2]. Of the several treatment methods available to improve in situ sand as well as the sandy soil used for land reclamation projects etc., cement treatment is one of the most straightforward methods with fewer limitations. The strength and stiffness of cement-treated sand are generally affected by several factors including the types and properties of the binding material/sand as well as the environmental factors such as curing conditions and pore-water properties [3-5]. The type of sands that generally need cement treatment are the poorly graded sands, as the well-graded ones can be stabilized by compaction methods. The mechanical properties of both uniformly graded sands and gap-graded sands can be improved by cement stabilization. Especially, uniformly graded sand with fines is one of the most problematic types of soils to improve through conventional treatment methods such as dynamic compaction or vibro-compaction. In addition, the presence of fines makes it difficult 
for the conventional treatments to be applied effectively. In this study, we investigate the influence of fine particles in cement-treated uniformly graded sand.

Previous studies on cemented sand have concentrated on clean sand that contains negligible proportion of fine particles, even though natural sands almost always contain fines (silt or clay or both) at varying proportions. Whereas there are studies in literature that have reported on the effects of fines on the behavior of un-cemented sand, such studies on cement-treated sand are very rare. Recently, Consoli et al. [6] has explored the effects of fine particles in cemented sand and reported that presence of fine particles increase the tensile strength and stiffness of the material. However, the fine contents considered in the study were silt sized particles in large proportion (i.e., 10-30\%). The behavior of un-cemented sand is not inherently influenced by the presence of clay or silt at lower proportions. The intergranular void ratio $\left(e_{g}\right)$, which is calculated with the volume of fine particles added to the volume of voids, does not alter much at lower fine contents (i.e., $<10 \%$ ) as the fine particles mostly occupy the void space in the sand skeleton rather than the contact points between the sand particles. Because of this, the angle of shearing resistance of the sand is not significantly altered when the clay proportion is maintained within $20 \%$ [7]. In addition, Thevanayagam [8] reported that a sand-silt mixture of particular intergranular void ratio would have almost the same shear strength as the pure sand of same void ratio.

On the other hand, there are visible effects on the behavior of un-cemented sands due to the presence of fine particles in larger proportions during monotonic and cyclic loading [9]. There are several factors that influence the behavior/ property of un-cemented sand with fines: (1) the mechanical behavior of the sand with non-plastic fine particles (i.e., silt) are affected by the gradation of sand/silt, mineralogy of silt, water content and of course the silt content [10]; (2) in addition to all the above mentioned factors, the sand with plastic fines (i.e., clay) are also influenced by the mineralogy and plasticity of clay [11]; (3) the methods of deposition or compaction, used for the preparation of sand-silt or sandclay mixtures, affect the properties of resulting un-cemented sand-fine mixtures $[12,13]$. With all these studies indicating that the fine particles are influential in modifying the nature of un-cemented sand, it is imperative that their effects on cemented sand should be explored as well. In addition, as far as cement hydration is concerned, the sand is generally assumed as chemically inert and the cement only reacts with water. However, with fines like kaolinite or montmorillonite this assumption may not hold as there are studies that have recorded the chemical interactions between cement and those minerals [14-16]. Therefore, it is possible that the fine particles at lower proportions, which can be generally ignored in case of un-cemented sands, might yield quite different results with cement, even at a small proportion. This study explores the effects of fines in such small proportions in cement-treated soils through ultrasonic pulse velocity (UPV), shear wave velocity $\left(V_{s}\right)$ and unconfined compressive strength (UCS).

\section{Materials and methodology}

The sand used in this study is a commercially available filter medium of uniform gradation. The properties of the pure sand are as follows: mean diameter $\left(D_{50}\right)=0.71 \mathrm{~mm}$; effective diameter $\left(D_{10}\right)=0.45 \mathrm{~mm}$; co-efficient of uniformity $\left(C_{u}\right)=1.78$; co-efficient of curvature $\left(C_{c}\right)=1.00$; specific gravity $\left(G_{s}\right)=2.65$. The fine content of the soil (percentage of fine particles in soil) is varied by replacing the sand with specific amount of dry kaolin powder. In this way sandkaolin mixtures of four different fine contents were prepared, namely $0 \%$ (i.e., pure sand), $1 \%, 3 \%$, and $5 \%$. As the objective is to investigate the effects of fine particles in a small fraction, the percentage of fine particles is restricted to 5\%. Figure 1 shows that the grain size distribution curves of the mixtures slightly altered because the kaolin powder is added in lieu of the equivalent mass of sand. The phase diagram shown in Fig. 2 explains how the amount of cement and water remain the same while kaolin replaces sand at different fine contents.

\subsection{OPC and CSA cements}

Two different types of cementitious binders are used in this study: (1) Ordinary portland cement (OPC-Type-I) and (2) Calcium sulfoaluminate cement (CSA). The mineral compositions of these two types of cements are listed in Table 1 . The OPC is one of the most commonly used binders

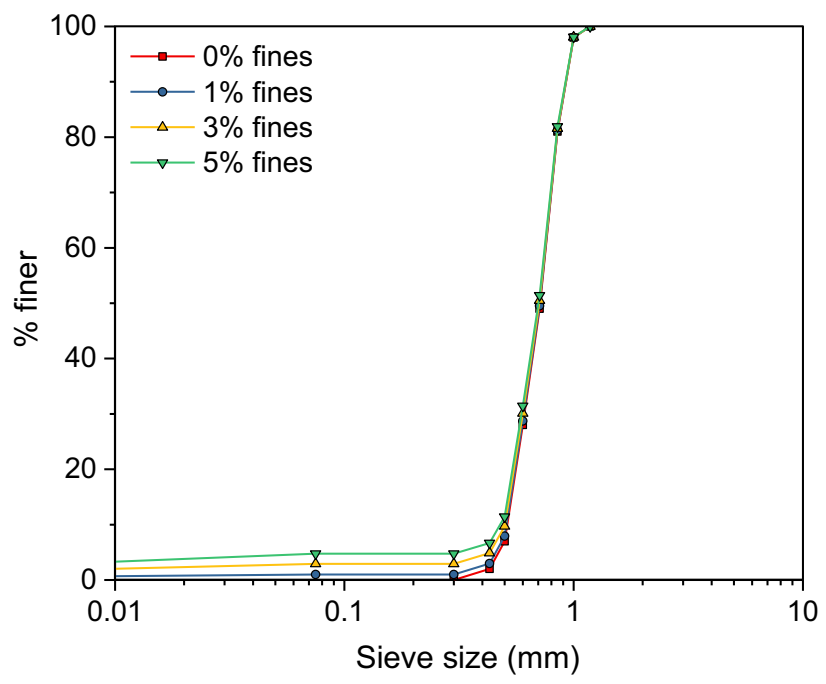

Fig. 1 Grain size distribution of the sand material 
Fig. 2 Phase diagram of samples of $7 \%$ cement content

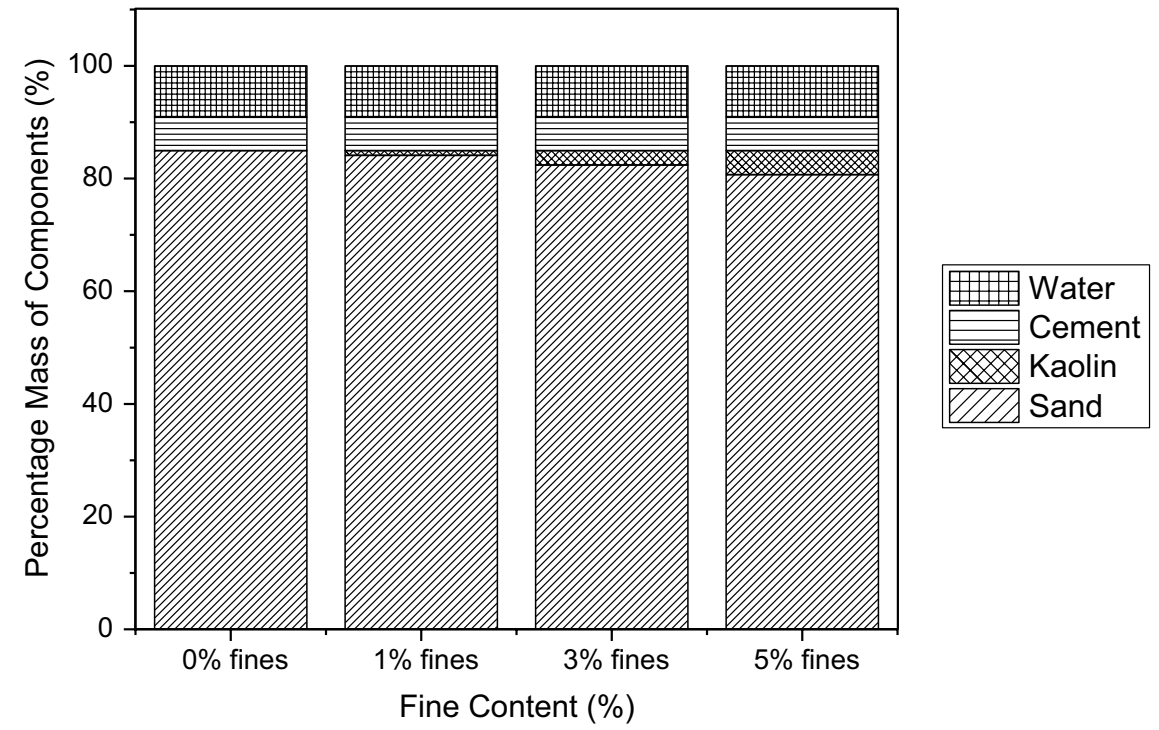

Table 1 Chemical composition of cements

\begin{tabular}{lllll}
\hline CSA & & & OPC \\
\cline { 1 - 1 } Component & \% by weight & & Component & \% by weight \\
\hline Ye'elimite & 47.7 & & Alite & 63.0 \\
Gypsum & 30 & & Belite & 24.3 \\
Belite & 13.7 & & Aluminate & 4.9 \\
Gehlinite & 2.1 & & Ferrite & 5.3 \\
Calcium titanate & 2.8 & & Anhydrite & 2.5 \\
Periclase & 0.9 & & & \\
Brownmillerite & 2.7 & & &
\end{tabular}

for ground improvement. Several studies have reported on the improved physical characteristics of OPC-treated sand/ clay $[17,18]$. The main components of OPC are alite (63\%) and belite $(24.3 \%)$. Although OPC-Type-I cement generally produces sufficient early strength in concrete, the initial strength (less than 1 day) in cement-treated soils is considerably smaller due to the relatively low cement content. In addition to its low early strength in cement-treated soils, the carbon-footprint of OPC manufacturing process is quite high. Therefore, alternate binding materials of lesser carbon emission and rapid strength gaining properties have been explored in the concrete industry. The CSA cement used in this study is one of such low-carbon, rapid-hardening alternative to the OPC.

CSA cement is becoming popular due to its high early strength, low carbon footprint, and high durability. The carbon dioxide emission during its manufacturing process is much lower compared to that of OPC. The main cementing phase of the CSA cement is ye'elimite that releases $63 \%$ less carbon dioxide during its synthesis compared to alite, which is the main cementing compound of OPC [19]. The ye'elimite reacts with gypsum and produces needle-shaped ettringite crystals at very early stage (i.e., before $24 \mathrm{~h}$ ). Therefore, CSA concrete has significantly higher strength in 1-day compared to OPC concrete. The 28-day strength of CSA concrete is equivalent to that of OPC [20]. Equation 1 shows the hydration reaction of ye'elimite with water and gypsum [21].

$$
\begin{gathered}
4 \mathrm{CaO} \cdot 3 \mathrm{Al}_{2} \mathrm{O}_{3} \cdot \mathrm{SO}_{3}+2 \mathrm{CaSO}_{4} \cdot 2 \mathrm{H}_{2} \mathrm{O}+32 \mathrm{H}_{2} \mathrm{O} \\
\rightarrow 6 \mathrm{CaO} \cdot \mathrm{Al}_{2} \mathrm{O}_{3} \cdot 3 \mathrm{SO}_{3} \cdot 32 \mathrm{H}_{2} \mathrm{O}+4 \mathrm{Al}(\mathrm{OH})_{3}
\end{gathered}
$$

Beside the use of the CSA cement in concrete industry, the CSA cement was recently employed as an alternative binding material for ground improvement in geotechnical engineering [5, 22, 23].

\subsection{Sample preparation}

Firstly, dry sand and kaolin powder are hand-mixed and then almost half-portion of water is added to the sand-kaolin mixture and mixed in a Hobart mixer for $5 \mathrm{~min}$. In case of $0 \%$ fines, only sand and water are mixed for $5 \mathrm{~min}$. Then, the cement (OPC or CSA) and the remaining half-portion of water are added and mixed for $10 \mathrm{~min}$ in the mixer. The mixture is compacted in PVC split-molds of diameter $50 \mathrm{~mm}$ and height $100 \mathrm{~mm}$. The interior of the molds is coated with lubricant gel to facilitate smooth extraction. The compaction is done in three layers in which each layer is compacted with a hand-held tamper. After the compaction, both ends of the molds are covered in polythene wrap and kept in water at room temperature $\left(24 \pm 1^{\circ} \mathrm{C}\right)$ for curing. The water is able to seep through the molds during the curing process, simulating the condition of wet curing. Five samples are prepared 
for each fine content, and the mean and standard deviation of its properties are represented in the plots.

\subsection{UPV and $V_{s}$ measurements}

The experimental schematic is shown in Fig. 3. After measurement of sample dimensions extracted after the specified curing period, ultrasonic pulse velocity (UPV) is measured through the Portable Ultrasonic Nondestructive Digital Indicating Tester (PUNDIT-7). The UPV is widely used for the assessment of strength and integrity of concrete as well as cemented soils, as an easily measurable indicator of strength and stiffness. There are several well-established correlations between the UPV and compressive strength of concretes and cemented soils. For example, the bulk modulus of the specimen measured by the UPV is a function of the bulk modulus of soil skeleton and pore water [24]. In addition, the increasing UPV with respect to the cement content and curing period shows that the stiffness and the strength of the samples are increasing due to the hydration process as well as forming and strengthening of cementitious bonds among particles over time.

During the UPV measurement, the sample is held between two transducers of diameter $50 \mathrm{~mm}$ (same as the samples) and of frequency $54 \mathrm{kHz}$. The interfaces between the transducers and the sample are coated with a lubricant to enable better coupling. The travel time of the ultrasonic pulse (in microseconds) is directly observed through the LED-panel in the PUNDIT-7. The travel time can also be verified with the waveform observed through the computer (Fig. 4a) in which the width of the transmitted wave is equal to the travel time. The UPV is simply calculated by dividing the length of the sample by the travel time. However, while measuring UPV, the sample should be held firmly between
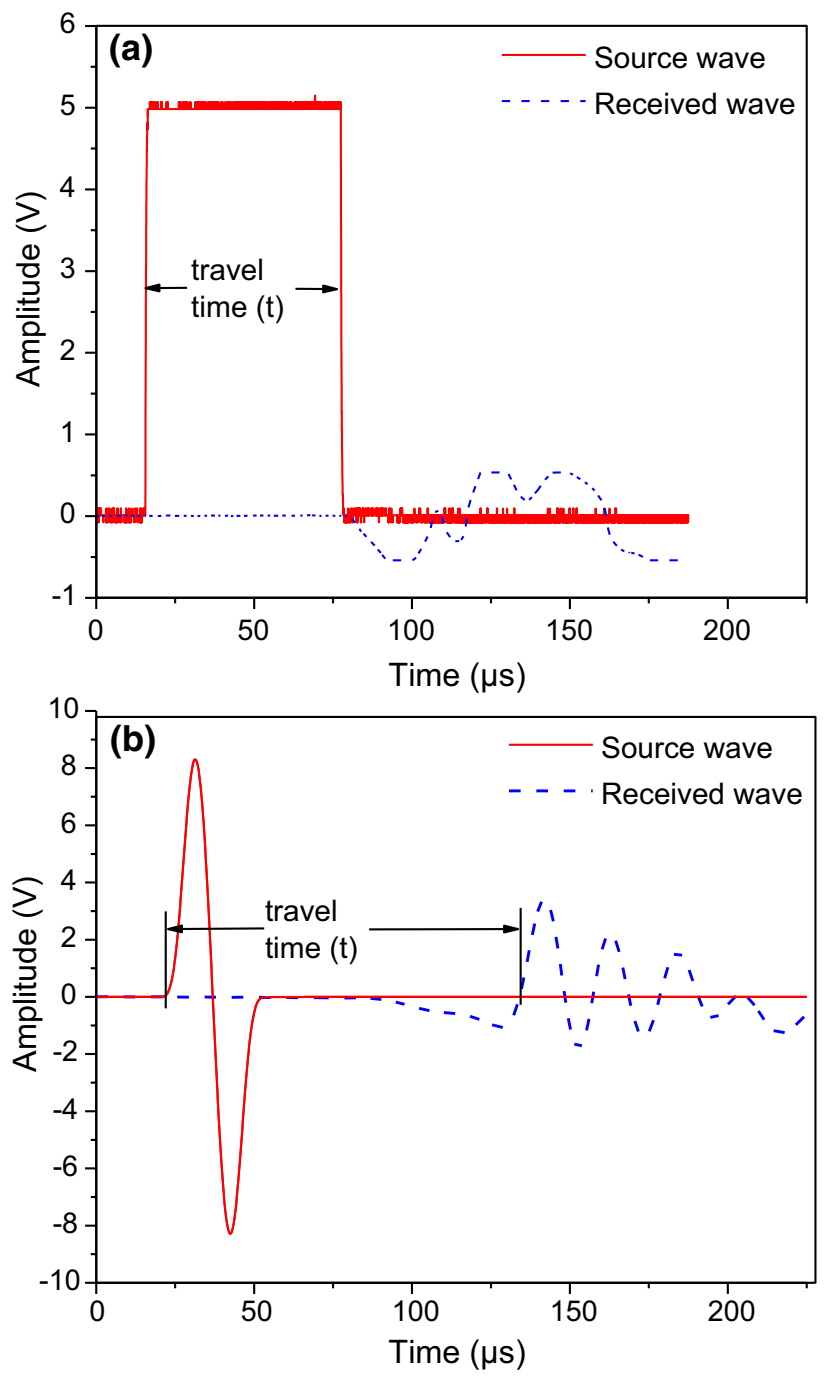

Fig. 4 a UPV signal, b $V_{s}$ signal

Fig. 3 Experimental test set-up

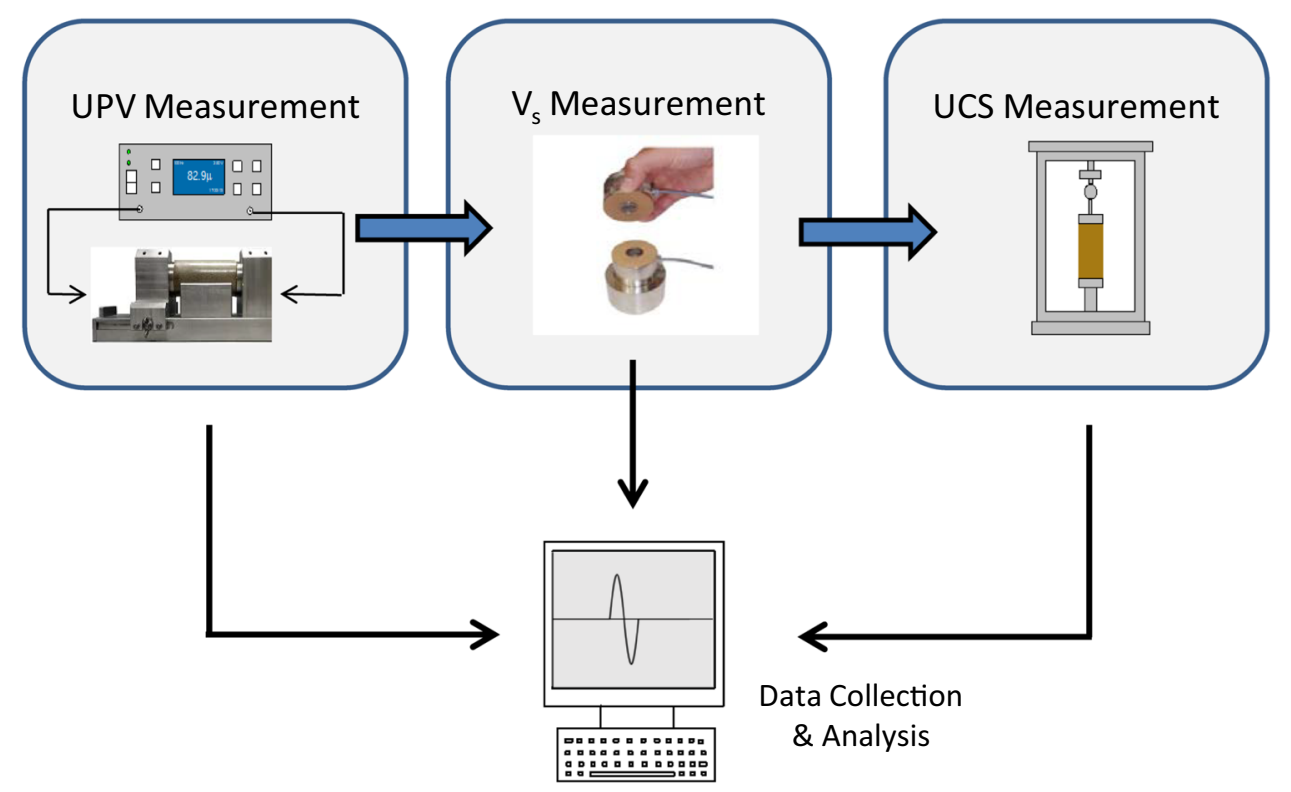


the transducers; thus, it may disturb and damage very soft samples (i.e., samples of low cement content and curing period). Because of this, the UPV of 3\% OPC (1-day and 7-day), 5\% OPC (1-day), 7\% OPC (0\% fines 1-day) samples could not be measured.

After obtaining the UPV data, the shear wave velocity $\left(V_{s}\right)$ of samples is measured through bender elements. In order to fit the benders, two grooves are cut on both sides of the sample, and packed with a filler material (modelling clay). The bender elements are inserted into the grooves, and snugly fit with the filler material. This helps in establishing good contact between the bender elements and the sample. The $V_{s}$ measurement system consists of a signal generator, a digital oscilloscope, a pair of bender elements and a desktop computer. Both the transmitted and received signals are acquired and stored in the computer.

The transmitted signals are sinusoidal waves of frequencies ranging from $2 \mathrm{kHz}$ to $35 \mathrm{kHz}$. The travel time is considered as the difference between the starting point of the transmitted wave and the first zero-crossing point of the received wave and the travelling distance is considered as the tip to tip distance between the bender elements. In order to eliminate the near-field effects during $V_{s}$ measurement, the length of sample to wavelength ratio $(\mathrm{L} / \lambda)$ should be more than 1 . In fact, the measured $V_{s}$ increases as $\mathrm{L} / \lambda$ ratio increases up to a certain extent, beyond which it remains almost constant. For soils, some studies have recommended to maintain a larger $L / \lambda$ ratio [25-27]. In this study, the $L / \lambda$ ratio for stiffer samples (i.e., $7 \%$ cement 28 -day samples) are between 2.6 and 3 and for other samples it is greater than 3.3. A sample wave-form observed from bender element test is shown in Fig. $4 b$.

\subsection{UCS measurement}

Unconfined compressive strength (UCS) test is a simple and standard test to directly evaluate the magnitude of strength development on concrete and cement-treated soils. After the UPV and $V_{s}$ measurements, the sample is tested in a universal compression machine at a constant deformation rate of $1 \mathrm{~mm} /$ minute until failure [28]. The peak stress during the test is considered as the compressive strength of the sample. However, at very low cement content and curing period, the UCS is very low and may not be representative.

\section{Results and analysis}

Figure 5 shows the variation of initial density and void ratio, measured right after the sample preparation, with respect to cement content, cement type and fine content. The void ratio of the mixture is a function of fines content, cement content,
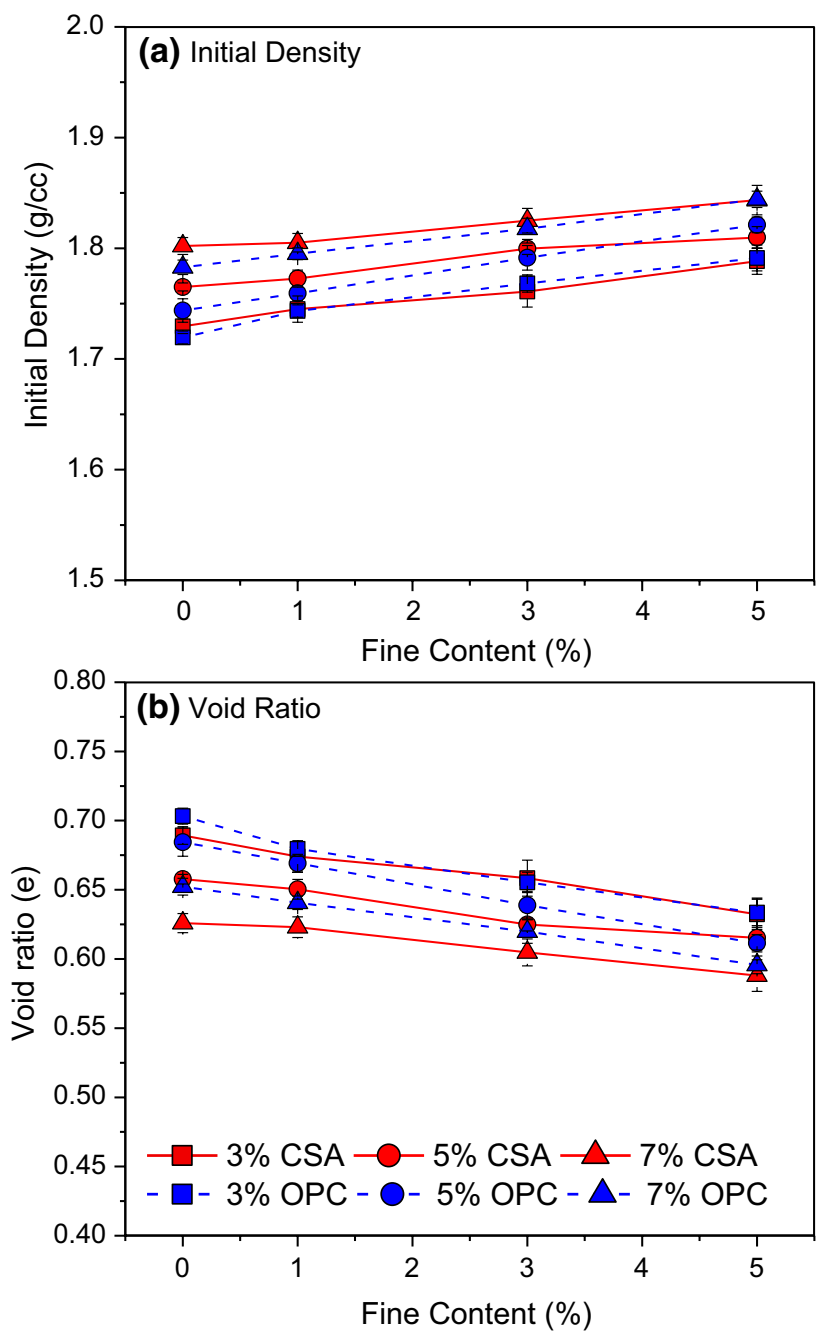

Fig. 5 a Initial density versus fine content, b void ratio versus fine content

water content and mass densities of sand, cement, kaolin and water. It is calculated from the measured bulk density as follows:

$\rho_{b}=\frac{\text { Total Mass }}{\text { Total Volume }}=\frac{M_{\text {solids }}+M_{\text {water }}}{V_{\text {solids }}+V_{\text {voids }}}=\frac{M_{\text {solids }}(1+w)}{V_{\text {solids }}(1+e)}$

$e=\left\{\frac{M_{\text {solids }}(1+w)}{V_{\text {solids }}\left(\rho_{b}\right)}\right\}-1$ 
$\frac{M_{\text {solids }}}{V_{\text {solids }}}=\frac{M_{s}+M_{k}+M_{c}}{V_{s}+V_{k}+V_{c}}=\frac{M_{s}\left(1+\frac{M_{k}}{M_{s}}+\frac{M_{c}}{M_{s}}\right)}{M_{s}\left(\frac{1}{\rho_{s}}+\frac{M_{k}}{\rho_{k} M_{s}}+\frac{M_{c}}{\rho_{c} M_{s}}\right)}=\frac{(1+F C+C C)}{\left(\frac{1}{\rho_{s}}+\frac{F C}{\rho_{k}}+\frac{C C}{\rho_{c}}\right)}$

$e=\left\{\frac{(1+F C+C C)(1+w)}{\left(\frac{1}{\rho_{s}}+\frac{F C}{\rho_{k}}+\frac{C C}{\rho_{c}}\right)\left(\rho_{b}\right)}\right\}-1$

where $\rho_{b}=$ bulk density; $w=$ water content; $e=$ void ratio; $F C=$ mass ratio between kaolin and sand; $C C=$ mass ratio between cement and sand; $\rho_{s}, \rho_{k}, \rho_{c}=$ mass densities of sand, kaolin and cement particles. It is evident from the figure that the density increases slightly with the cement content and with fine content for a particular cement content. Consequently, the void ratio decreases with cement content and fine content as more fine particles (i.e. cement and kaolin) are added, they fill the voids of sand skeleton, thereby decreasing the void ratio and increasing the density, slightly.

While comparing the densities and void ratios of samples with no fines, it can be seen that the CSA-treated samples are marginally denser than the OPC-treated samples. This happens despite the fact that both cements have similar grain size distribution and OPC has a greater specific gravity. However, with increasing fine content, the difference between the densities and void ratios of CSA- and OPCtreated samples of a particular cement content decreases, with OPC-treated samples even surpassing the CSA-treated ones at higher fine contents. Since samples are prepared with same water content and compaction effort, it can be deduced that CSA without fines is more effective than OPC as a binding material to achieve greater density. On the contrary, with addition of fines OPC becomes more effective in obtaining denser samples.

\subsection{Effect of cement type and fine content on UPV and $V_{s}$}

The variation of UPV and $V_{s}$ with respect to fine content are shown in Fig. 6. In general, both UPV and $V_{s}$ increase with cement content, fine content and curing period, which represent the increase in strength and stiffness with those parameters. It should be noted that some missing OPC data at lower cement content and/or early curing period are attributed to insufficient strength development of the samples. The CSAtreated samples, at one day, have achieved 1.5 to 2 times the UPV and $V_{s}$ of corresponding OPC-treated samples. This shows rapid strength and stiffness gaining capability of CSA. As the cement content increases, it can be observed that the UPV and $V_{s}$ of CSA treated samples do not increase as much with the curing time as those of OPC. The difference between 1-day and 7-day UPV and $V_{s}$ are getting lower as CSA cement content increases. The 7-day UPV and $V_{s}$ are almost equivalent to those of 28-day.

On the contrary, the difference between 1-day and 7-day UPV and $V_{s}$ of OPC-treated samples becomes higher as the cement content increases. The 1-day UPV and $V_{s}$ of OPCtreated samples are considerably lower than those of CSAtreated samples, as expected. The 7-day UPV and $V_{s}$ of OPC-treated samples are lower than those of CSA-treated samples at $0 \%$ and $1 \%$ fine content. However, as the fine content increases, the difference between CSA- and OPCtreated samples becomes lower and lower. At 3\% and 5\% fine content, the 7-day UPV and $V_{s}$ of OPC-treated samples are slightly greater than the corresponding velocities of CSAtreated samples. This difference between 7-day UPV and $V_{s}$ values of OPC- and CSA treated samples at 3\% and 5\% fine contents are the highest at $3 \%$ cement content and decreases as cement content increases.

The 28-day UPV and $V_{s}$ for CSA-treated samples is lesser than those of OPC-treated samples at 3\% and at 5\% cement contents, but they are almost equal at $7 \%$ cement content. The CSA-treated samples without fines achieve almost equivalent level of UPV and $V_{s}$ of OPC-treated samples. As the fine content increases, the difference between UPV and $V_{s}$ of OPC- and CSA-treated samples also increases, but the difference is not as significant at higher cement contents (2\% difference at $7 \%$ cement content) as at lower cement contents ( $18 \%$ difference at $3 \%$ cement content). Whereas both UPV and $V_{s}$ increase with increasing fine content, the rate of increase in UPV and $V_{s}$ is generally higher for OPCtreated samples. Also, in OPC-treated samples, this rate of increase in UPV and $V_{s}$ with respect to fine content is getting decreased as the cement content increases. For example, the average UPV of OPC-treated samples of 5\% fine content is 1.45 times the average UPV of samples with no fines at $3 \%$ cement content and 28-day curing period. At the same curing period, but at $7 \%$ cement content, the average UPV of OPC-treated samples with 5\% fine content is only 1.06 times the average UPV of samples with no fines. This shows that the effects of fine particles reduce at higher cement contents.

Another important observation from Fig. 6 is that the OPC-treated samples gain stiffness faster with time in higher fine content. The difference between the 7-day and 28-day UPV and $V_{s}$ of OPC-treated samples shrinks as the fine content increases. The magnitude of this shrinking reduces as the cement content increases. For example, at OPC 3\% 

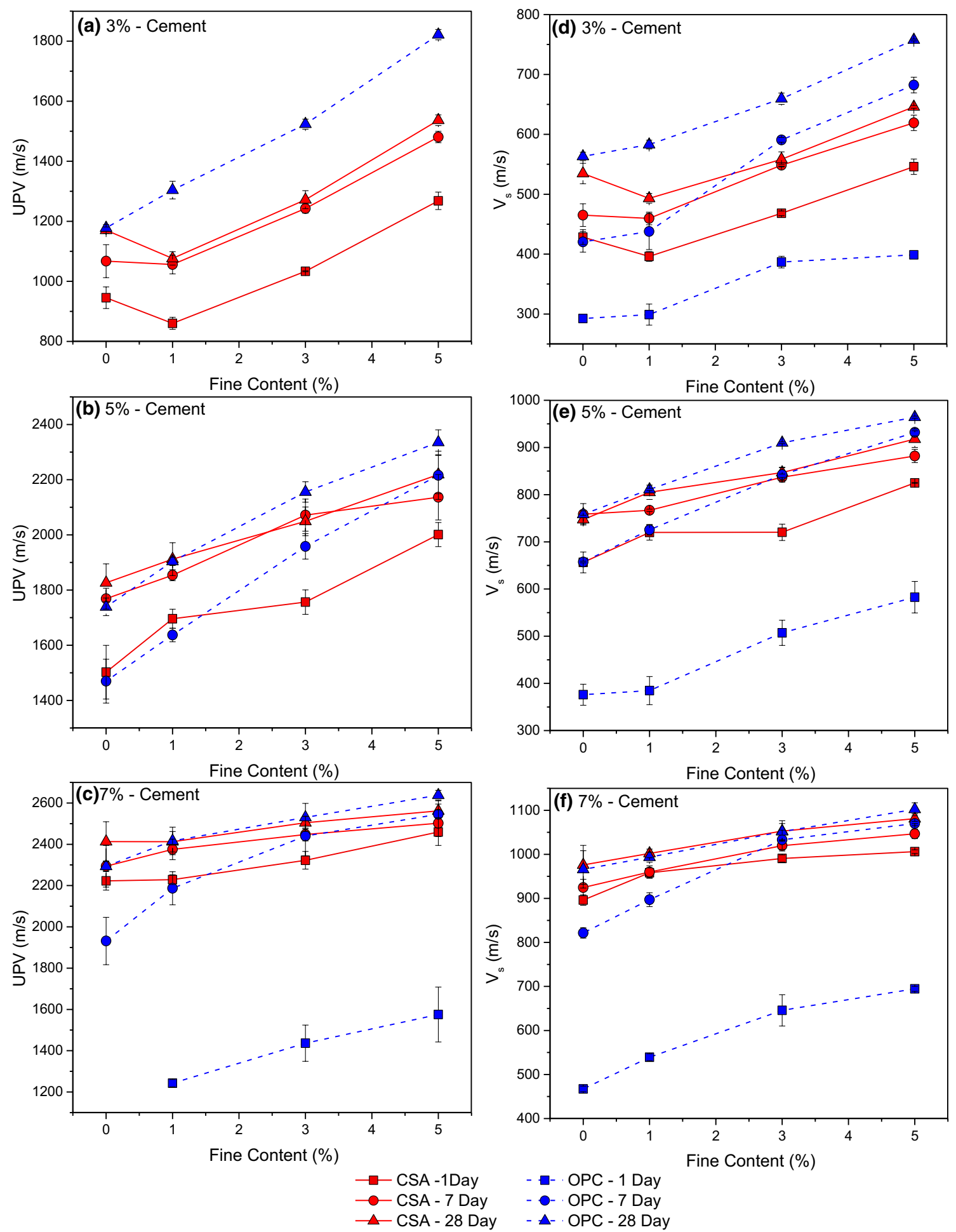

Fig. 6 UPV versus fine content a 3\% cement, b 5\% cement, c 7\% cement and $V_{s}$ versus fine content d $3 \%$ cement, e 5\% cement, f $7 \%$ cement

cement content, the ratio of $V_{s}$ at 28-day and 7-day with 5\% fines is 1.11 , and the same ratio with no fines is 1.33 . On the contrary, at OPC $7 \%$ cement content, the ratio of 28 day and 7 day with 5\% fines is 1.03 and the same ratio with no fines is 1.18 . From geotechnical standpoint, both clay and cement have affinity towards water. In this regard, the strength of cemented sample depends on the amount water available for hydration of cement $[29,30]$ and the behavior of clay is dependent on its water content [31]. At higher fines content ( $5 \%$ fines content), it is possible that more 

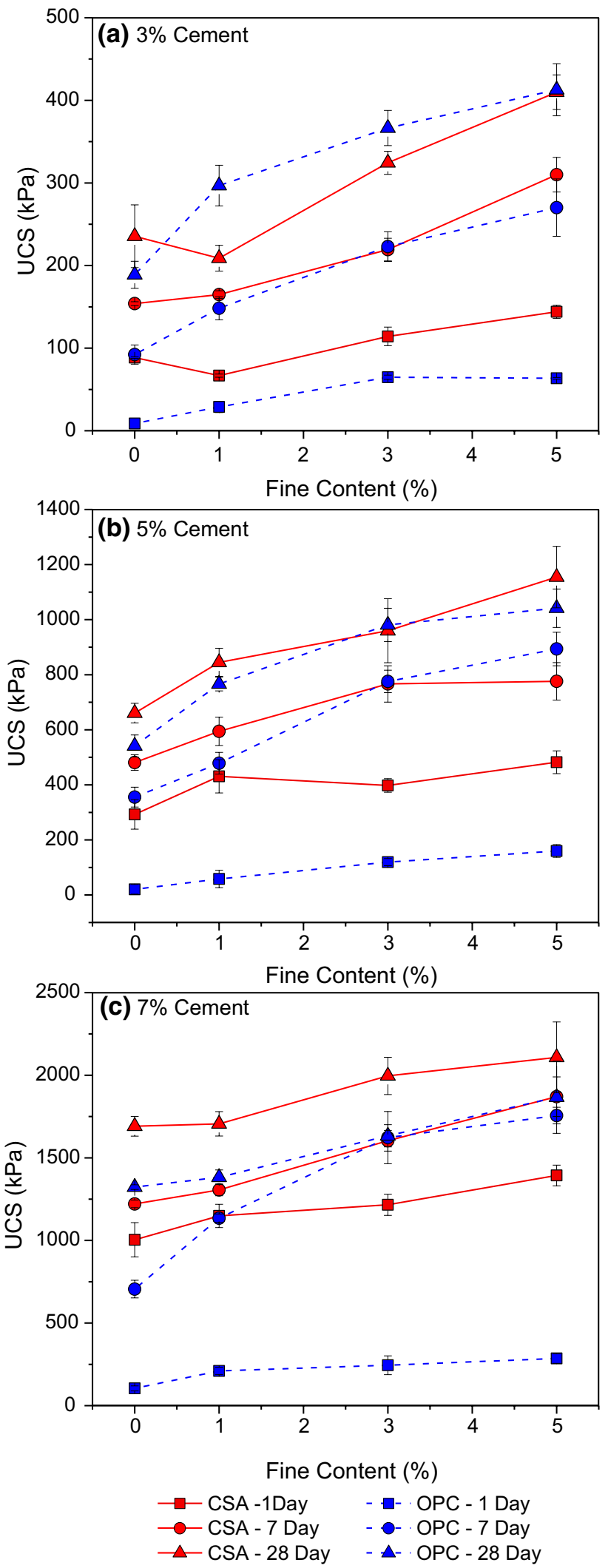

Fig. 7 UCS with fine content a $3 \%$ cement, b 5\% cement, c 7\% cement

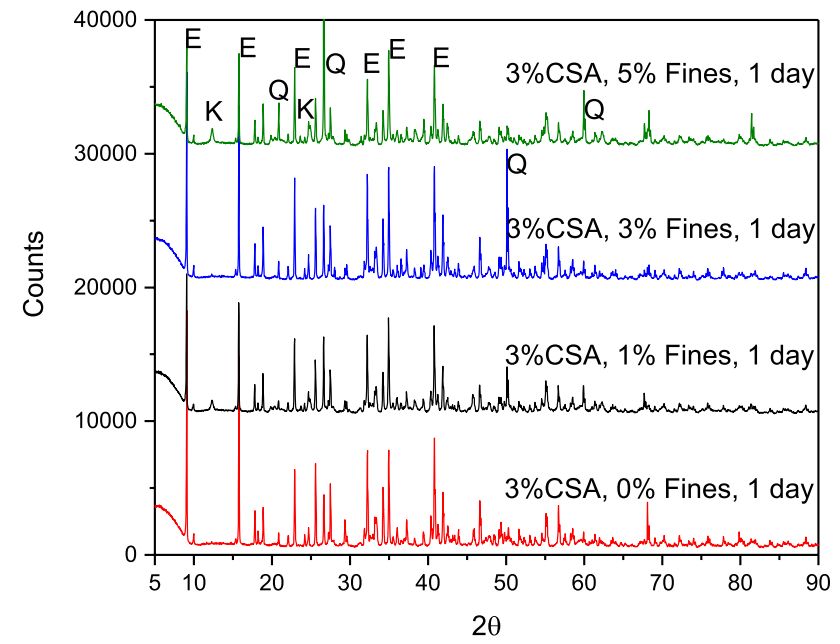

Fig. 8 X-Ray Diffraction test results of 3\% CSA samples with different fine contents. (Note: peaks marked with ' $E$ ', ' $K$ ' and ' $Q$ ' denote ettringite, kaolinite and quartz respectively)

water is absorbed by the clay compared to $0 \%$ or $1 \%$ or $3 \%$ fines content leaving less water available for hydration of cement. So, the actual water to cement ratio (the amount of water actually available for hydration after some water got absorbed by clay), reduces with increasing fine content. It is widely accepted that the reduction in water to cement ratio causes an increase in strength. Therefore, an increase in wave velocities and strength is observed with increasing fine content. This reduction in water due to the presence of clay could have caused smaller rate of stiffness gain for samples with higher fines content.

\subsection{Effect of cement type and fine content on UCS}

The UCS of the cement-treated sand is plotted against fine content for three cement contents in Fig. 7. The cementtreated samples generally show increase in strength with cement content and with fine content for all curing periods. 1-day strengths of CSA-treated samples are higher than those of OPC-treated samples and this difference increases with cement content. In addition, while there is improvement between 7-day and 28-day strength in CSA-treated samples at all fine contents and cement contents, OPC treated samples do not show improvement in that period at higher cement contents and higher fine contents.

As observed in UPV and $V_{s}$ in Fig. 6, the 7-day strength of OPC-treated sand is less at $0 \%$ and $1 \%$ fine content while equivalent or greater at $3 \%$ and $5 \%$ fine content, compared to that of CSA-treated samples. At 28-days, the absolute difference between UCS of CSA and OPC treated samples varies from $47 \mathrm{kPa}$ at $3 \%$ cement content to $368 \mathrm{kPa}$ at $7 \%$ cement content. This indicates that at higher cement contents, for 

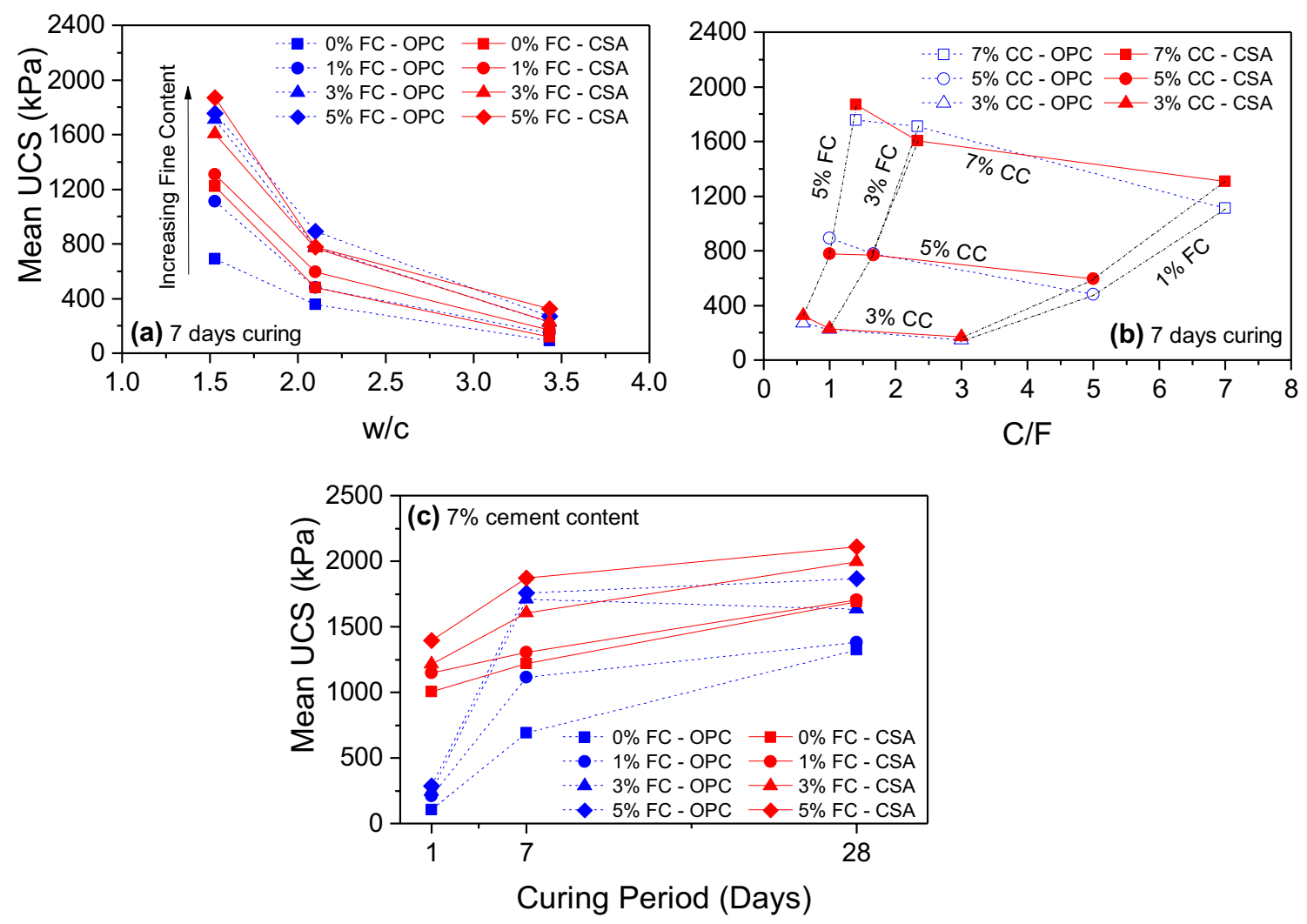

Fig. 9 Mean UCS with varying fine content considering the effect of a water to cement ratio at 7 day curing time, $\mathbf{b}$ cement to fines ratio at 7 day curing time, $\mathbf{c}$ curing time at $7 \%$ cement content. (Note: FC-

the same range of UPV and $V_{s}$, CSA-treated samples show higher strength than those of OPC.

Interestingly, there are a few positions in CSA-treated sand where the UCS decreases slightly with increasing fine content: (1) $3 \%$ cement content, 1-day curing period, between $0 \%$ fines and $1 \%$ fines; (2) 5\% cement content, 1-day curing period, between $1 \%$ fine content and 3\% fine content. In order to investigate the reasons, X-Ray Diffraction (XRD) tests were conducted on 3\% CSA-samples of 1-day curing period. However, Fig. 8 presents that there are no major differences between the samples of different fine contents, which show the development of ettringite. It is possible that the physical arrangement of particles of different sizes and their interaction with cementitious products could lead to these incongruities. However, it is hard to speculate the causes for this behavior and further study in the interactions of cemented sand with fines might shed light on this phenomenon.

On the other hand, the effects of fine content can be further validated in conjunction with exploring other factors that would also be important for characterizing UCS. For instance, Fig. 9 shows the effects of (1) water to cement ratio $(\mathrm{w} / \mathrm{c})$ and cement to fines ratio $(\mathrm{C} / \mathrm{F})$ at 7 day curing time, fine content, $\mathrm{CC}-$ cement content, $\mathrm{C} / \mathrm{F}$ - cement to fines ratio and w/c-water to cement ratio)

and (2) curing time at $7 \%$ cement content on mean UCS with varying fine content. Figure $9 \mathrm{a}$ presents the development of the mean UCS with three different water to cement ratio (i.e., 1.5, 2.1, and 3.4) for each cement content at 7 day curing time. The strength for a given water to cement ratio increased with an increase in fine content, while the strength for a given fine content decreased with an increase in water to cement ratio. Figure $9 b$ shows the variation of mean UCS with different cement to fines ratios at 7 day curing time. In Fig. 9b, the vertically inclined lines represent the mean UCS obtained by the same fine contents with different cement contents while the horizontally inclined ones are obtained by the same cement content with different fine contents. For a given cement/fine content, the strength increased with an increase in fine/cement content, respectively. The increase in cement content leads to more hydration reactions for a given fine content, while the increase in fine content may result in more number of contacts between soil particles for a given cement content. Especially, it is clearly observed in Fig. $9 \mathrm{~b}$ that the strength increase rate (i.e., slope) increases rapidly with increasing fine content. Figure $9 \mathrm{c}$ compares the development of the mean UCS for 7\% cement content with respect to the curing period. It was also observed that the 

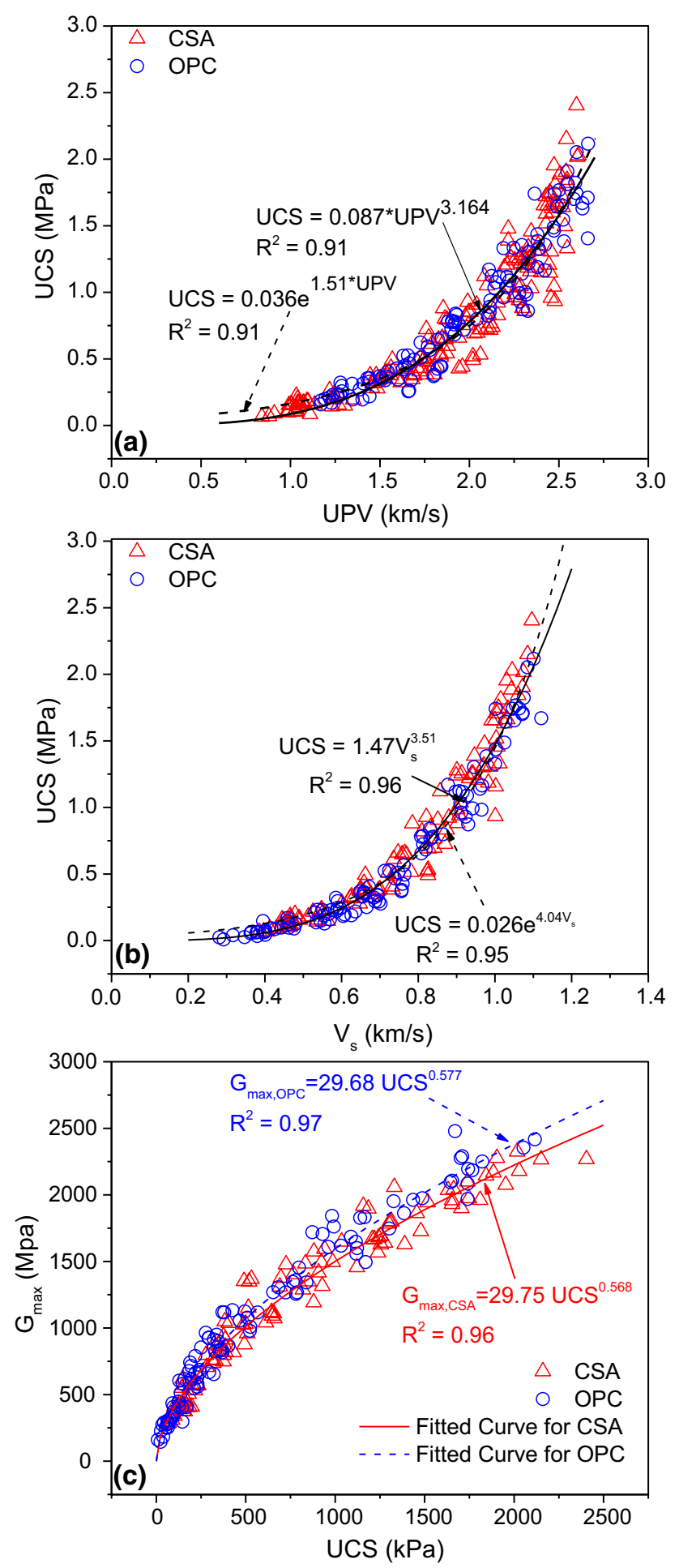

Fig. 10 Relationships a UPV versus UCS, b $V_{s}$ versus UCS, c $G_{\max }$ versus UCS mean UCS at a given curing time generally increases with increasing fine content.

\section{$3.3 V_{s}$ and UPV versus UCS}

It is very beneficial to develop correlations between the compressive strength and wave velocities, which can be measured in situ and quite expeditiously, as a tool for monitoring and quality control. Both UPV and $V_{s}$ are applicable as non-destructive indictors of strength development in cement treated soils. There are many correlations established between UPV and UCS, generally for concretes [32, 33]. Some studies have explored relationships between UPV and compressive strength of cemented soils as well [34]. Using the compiled data in this study, Fig. 10a, b show apparent relationships of the compressive strength with UPV and $V_{s}$ respectively. There are two types of mathematical relationships established: (1) power relationship $\left(\mathrm{y}=\mathrm{a} \cdot x^{b}\right)$ and (2) exponential relationship $\left(\mathrm{y}=\mathrm{a} \cdot e^{b x}\right)$. It can be observed from the figures that both correlations fit quite well with the data. Figure 10a shows an even scatter of compressive strengths of OPC- and CSA-treated samples with respect to the UPV, whereas Fig. 10b presents greater compressive strengths of CSA-treated samples than those of OPCtreated samples at particularly higher $V_{s}$. This effect can be more clearly seen in Fig. 10c, which is plotted between small strain shear modulus $\left(G_{\max }\right)$ and UCS. It indicates that CSA-treated samples have less stiffness than OPC-treated samples, at similar compressive strength. This shows that the UCS- $G_{\max }$ relationship depends upon the type of binding material used.

\section{Discussion}

Whereas it is evident that any fine particles in a cemented sand system would influence its behavior, it is apparent that even at an insignificant proportion (i.e. $<5 \%$ ), the fine particles exert significant influences (75-100\% increase in strength at $3 \%$ cement content) on the behavior of cemented sand. The proportion of fines used in this study is quite small, which has been generally ignored during design and analysis on cement treated soil improvement. While this may not affect the un-cemented sand in any considerable way, the results from this study prove that it may not be the case in cemented sand. Apart from demonstrating that fines at smaller proportions cannot be ignored while designing a 
Fig. 11 SEM images a CSA$0 \%$ fines, b CSA $5 \%$ fines, c OPC $0 \%$ fines, $\mathbf{d}$ OPC $5 \%$ fines
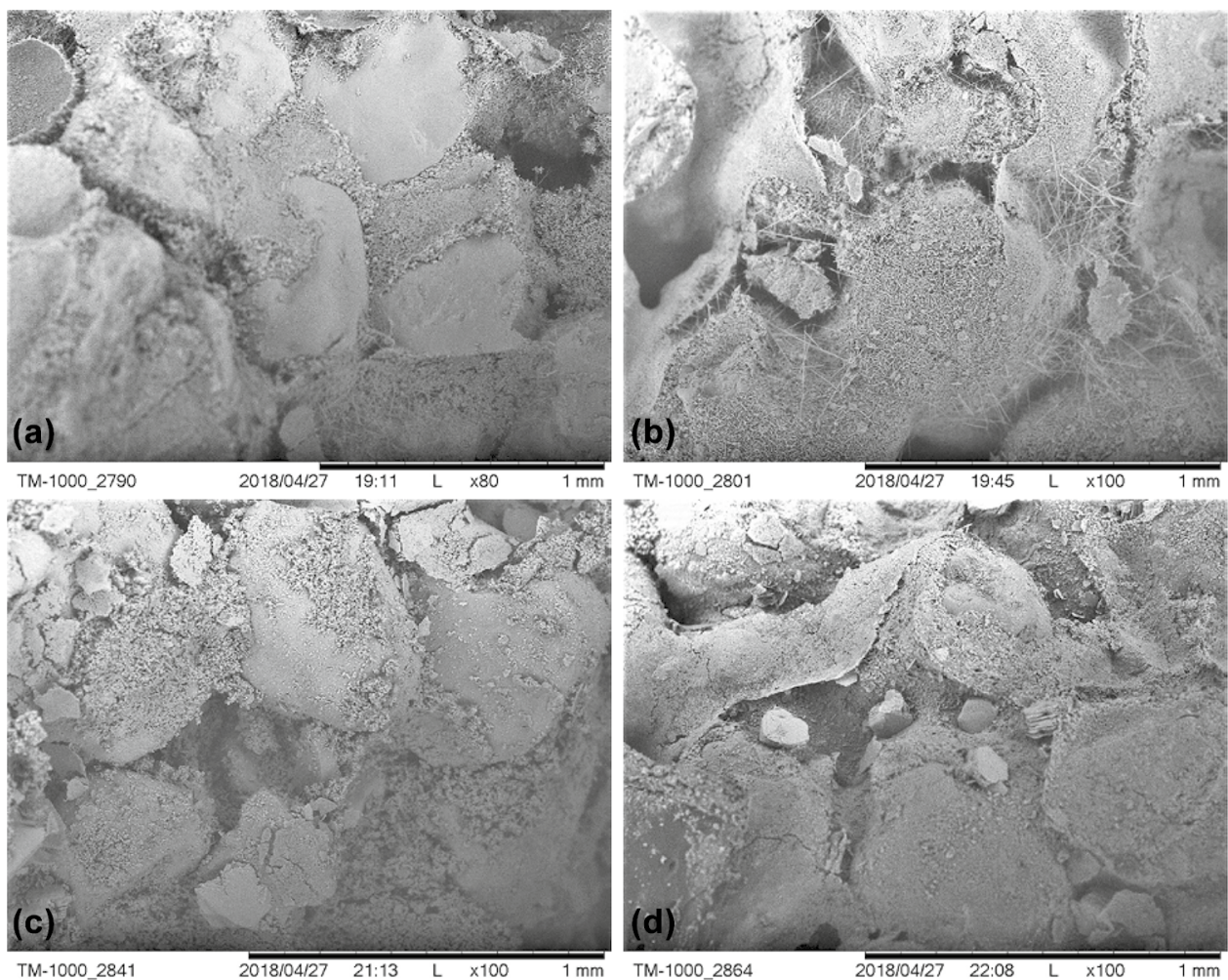

TM-1000_2801

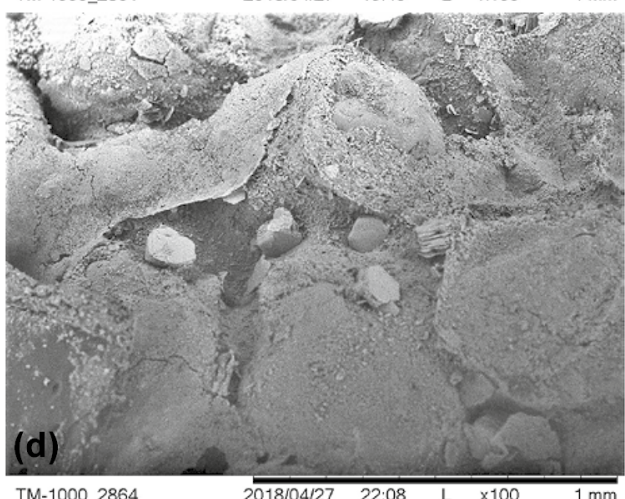

cemented sand system, this section of the paper attempts to explain some of the inferences from the results and analysis.

The general increase in strength of both OPC-treated samples and CSA-treated samples, at 28-days, with fine content can be explained if the cement and fine particles are considered as 'fine fraction' of the material. The larger the 'fine fraction', up to the extent considered in this study, the higher the density, the co-ordination number and consequently the strength and stiffness. With more amount of fine fraction, it can be postulated the bonds increase their contact area in a dense coarse skeleton which might result in higher stiffness, albeit the low reactivity of kaolinite. However, one of the most interesting findings from the experimental results would be the 7-day strength of OPC-treated samples, in which the strength increase is quite significant compared to the other two curing period. This phenomenon is discussed in the following paragraph.

Naturally available soils, especially sands, have different kinds of fine materials at different proportions. The fine fraction of any soil might include, silt, kaolinite, illite, montmorillonite, etc. and different fine particles may react differently with a binding material. The fine particles used in this study are kaolin. The studies that have reported on OPC-treated clays have observed a pozzolanic reaction occurring between kaolin and the hydrated lime which is a byproduct of the primary hydration reactions of OPC. During the hydration of both alite and belite, which are the primary components of OPC, calcium silicate hydrates $(\mathrm{C}-\mathrm{S}-\mathrm{H})$ are produced along with hydrated lime (portlandite) [35]. The C-S-H gel is the compound that provides strength during and after the hydration. Whereas it is observed that kaolinite undergoes a pozzolanic reaction with lime after 7 days, which could be one of the causes for increasing strength with fine content, in the current study no significant increase in strength between 7 and 28 days was observed. Therefore, the increasing strength with increasing fine content may primarily be due to the fine particles acting as a filler material and increased density with fine content [36]. In Fig. 11, the SEM images demonstrate that with more fines the cementitious materials precipitated between the particle contacts are more.

Figure 12 shows the relationships between the fines content and the 7- and 28-day strength of samples normalized by the strength of $0 \%$ fines (i.e., cemented pure sand) of corresponding cement content and curing time. It shows the reducing trend of the effect of fines with increasing cement content, which can be understood through two possible mechanisms: (1) with increasing cement content, the proportion of kaolin with respect to the cement content reduces; (2) whereas the amount of hydrated lime increases with increasing cement content, the amount of kaolin that can react with remains constant. For example, the proportion of kaolin in the mixture of 3\%-cement and $5 \%$-fines is $62.5 \%$ whereas it is $41.7 \%$ in $7 \%$-cement and 5\%-fines mixture. Therefore, as the cement content increases, the effect of fines slightly decreases. In OPCtreated samples, the amount of hydrated lime produced as 

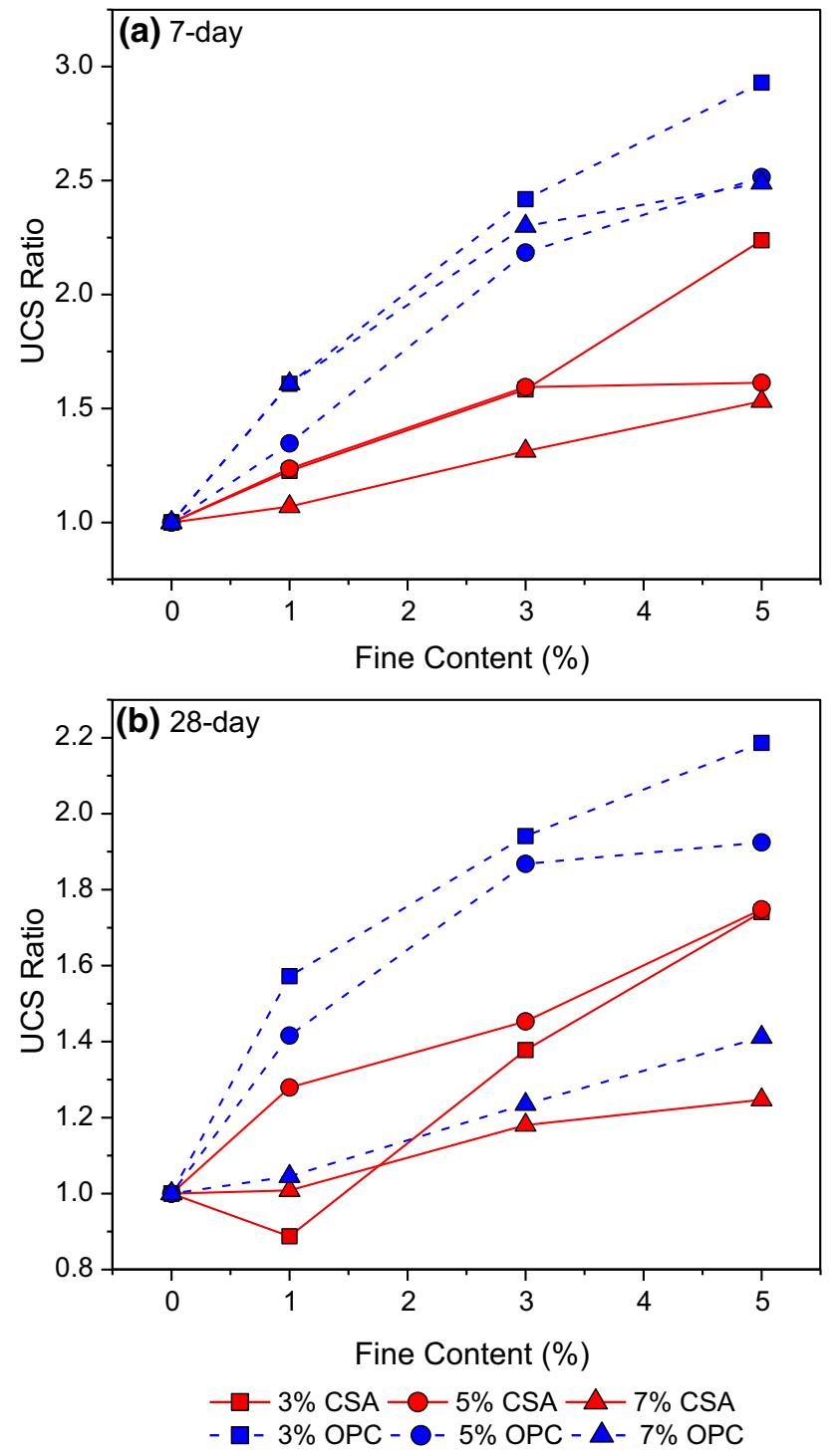

Fig. 12 UCS ratio normalized with $0 \%$ fines a 7-day and b 28-day

a byproduct of OPC hydration generally increases with increasing the cement content. However, at a particular fine content, the amount of kaolin that the hydrated lime can react with to produce additional cementitious material remains the same. This also explains the slight decrease in the effect of fines with increasing cement content.

\section{Summary and conclusions}

The effects of fine particles in the strength development of cement-treated sand were studied, with two different types of cement, three cement contents and four fine contents. Industrial grade kaolin powder was used as fine particles. The strength and stiffness development was measured through ultrasonic pulse velocity (UPV), shear wave velocity $\left(V_{s}\right)$ and unconfined compressive strength (UCS). The main conclusions derived from this study are:

(a) There are significant effects in the strength and stiffness development of cement-treated soil due to the presence of a small amount of fines regardless of cement type.

(b) The effects of fines vary with cement type, cement content, curing period, mineralogy of the fine fraction of the soil, and any possible chemical reaction between fines and binding material or the byproducts of the hydration reaction.

Even though the effects observed in this study apply particularly to the cements, sand and kaolin used in this study, it is established that the small amount of fine particles cannot be ignored in the design of a cemented sand system. In order to better understand these effects, it is recommended that the study be expanded considering different types of fines such as bentonite, non-plastic silt and blends of these fines of different proportion. Besides different types of fines, different types of binding materials should also be considered in the future study.

Acknowledgement The authors appreciate the financial support from Singapore Ministry of Education (MOE, Award Number: R-302-000-194-114) and the Nazarbayev University (Grant No: 110119FD4508). The constructive comments of the reviewers, which helped in improving the quality of the paper, are also gratefully acknowledged.

\section{Compliance with ethical standards}

Conflict of interest The authors declare that there is no conflict of interest.

Open Access This article is distributed under the terms of the Creative Commons Attribution 4.0 International License (http://creativeco mmons.org/licenses/by/4.0/), which permits unrestricted use, distribution, and reproduction in any medium, provided you give appropriate credit to the original author(s) and the source, provide a link to the Creative Commons license, and indicate if changes were made.

\section{References}

1. Consoli, N.C., Cruz, R.C., Floss, M.F., Festugato, L.: Parameters controlling tensile and compressive strength of artificially cemented sand. J. Geotech. Geoenviron. Eng. 136(5), 759-763 (2009)

2. Clough, G.W., Sitar, N., Bachus, R.C., Rad, N.S.: Cemented sands under static loading. J. Geotech. Geoenviron. Eng. 107, 799-817 (1981)

3. Consoli, N.C., Viana da Fonseca, A., Cruz, R.C., Heineck, K.S.: Fundamental parameters for the stiffness and strength control of artificially cemented sand. J. Geotech. Geoenviron. Eng. 135(9), 1347-1353 (2009) 
4. Wei, X., Ku, T.: New design chart for geotechnical ground improvement: characterizing cement-stabilized sand. Acta Geotech. (2019). https://doi.org/10.1007/s11440-019-00838-2

5. Subramanian, S., Khan, Q., Ku, T.: Strength development and prediction of calcium sulfoaluminate treated sand with optimized gypsum for replacing OPC in ground improvement. Const. Build. Mater. 202, 308-318 (2019). https://doi.org/10.1016/j.conbuildma t.2018.12.121

6. Consoli, N.C., Carretta, M.S., Leon, H.B., Schneider, M.E.B., Reginato, N.C., Carraro, J.A.H.: Behaviour of cement-stabilised silty sands subjected to harsh environmental conditions. Proc. Inst. Civil Eng. Geotech. Eng. (2019). https://doi.org/10.1680/jgeen .18 .00243

7. Georgiannou, V., Burland, J., Hight, D.: The undrained behaviour of clayey sands in triaxial compression and extension. Geotechnique 40(3), 431-449 (1990)

8. Thevanayagam, S.: Effect of fines and confining stress on undrained shear strength of silty sands. J. Geotech. Geoenviron. Eng. 124(6), 479-491 (1998)

9. Paydar, N.A., Ahmadi, M.M.: Effect of fines type and content of sand on correlation between shear wave velocity and liquefaction resistance. Geotech. Geol. Eng. 34(6), 1857-1876 (2016)

10. Belkhatir, M., Arab, A., Schanz, T., Missoum, H., Della, N.: Laboratory study on the liquefaction resistance of sand-silt mixtures: effect of grading characteristics. Granul. Matter 13(5), 599-609 (2011)

11. Papadopoulou, A.I., Tika, T.M.: The effect of fines plasticity on monotonic undrained shear strength and liquefaction resistance of sands. Soil Dyn. Earthq. Eng. 88, 191-206 (2016)

12. Yamamuro, J.A., Wood, F.M.: Effect of depositional method on the undrained behavior and microstructure of sand with silt. Soil Dyn. Earthq. Eng. 24(9-10), 751-760 (2004)

13. Deb, K., Sawant, V., Kiran, A.: Effects of fines on compaction characteristics of poorly graded sands. Int. J. Geotech. Eng. 4(2), 299-304 (2010)

14. Chemeda, Y.C., Deneele, D., Christidis, G.E., Ouvrard, G.: Influence of hydrated lime on the surface properties and interaction of kaolinite particles. Appl. Clay Sci. 107, 1-13 (2015)

15. Vitale, E., Deneele, D., Paris, M., Russo, G.: Multi-scale analysis and time evolution of pozzolanic activity of lime treated clays. Appl. Clay Sci. 141, 36-45 (2017)

16. Herzog, A., Mitchell, J.K.: Reactions accompanying stabilization of clay with cement. Highw. Res. Rec. 36, 146-171 (1963)

17. Ho, L.S., Nakarai, K., Duc, M., Le Kouby, A., Maachi, A., Sasaki, T.: Analysis of strength development in cement-treated soils under different curing conditions through microstructural and chemical investigations. Constr. Build. Mater. 166, 634-646 (2018)

18. Amir-Faryar, B., Suter, K.E., Finnen, R.E.: Strength of cement treated piedmont residual silty soils. Geotech. Geol. Eng. 35(4), 1819-1830 (2017)

19. Gartner, E.: Industrially interesting approaches to "low- $\mathrm{CO}_{2}$ " cements. Cem. Concr. Res. 34(9), 1489-1498 (2004)

20. Zajac, M., Skocek, J., Bullerjahn, F., Haha, M.B.: Effect of retarders on the early hydration of calcium-sulpho-aluminate (CSA) type cements. Cem. Concr. Res. 84, 62-75 (2016)

21. Ukrainczyk, N., Frankoviæ Mihelj, N., Šipušić, J.: Calcium sulfoaluminate eco-cement from industrial waste. Chem. Biochem. Eng. Q. 27(1), 83-93 (2013)
22. Vinoth, G., Moon, S.W., Moon, J., Ku, T.: Early strength development in cement-treated sand using low-carbon rapid-hardening cements. Soils Found. 58(5), 1200-1211 (2018). https://doi. org/10.1016/j.sandf.2018.07.001

23. Subramanian, S., Moon, S.-W., Moon, J., Ku, T.: CSA-treated sand for geotechnical application: microstructure analysis and rapid strength development. J. Mater. Civil Eng. 30(12), 04018313 (2018)

24. Leong, E., Cheng, Z.: Effects of confining pressure and degree of saturation on wave velocities of soils. Int. J. Geomech. 16(6), D4016013 (2016)

25. Leong, E.C., Cahyadi, J., Rahardjo, H.: Measuring shear and compression wave velocities of soil using bender-extender elements. Can. Geotech. J. 46(7), 792-812 (2009)

26. Khan, Q., Subramanian, S., Wong, D.Y., Ku, T.: Bender elements in stiff cemented clay: shear wave velocity correction by applying wavelength considerations. Can. Geotech. J. 56(7), 1034-1041 (2019)

27. Moon, S.W., Zhanar, B., Khan, Q., Ku, T.: Discussion on "Shear wave velocity of zeolite-cement grouted sands", by Afshin Kordnaeij, Reza Ziaie Moayed and Majid Soleimanib [Soil Dyn Earthq Eng 122 (2019) 196-210]. Soil Dynamics and Earthquake Engineering (in press)

28. ASTM D2166. Standard test method for unconfined compressive strength of cohesive soil. ASTM International (1991)

29. Mindess, S., Young, J., Darwin, D.: Concrete. Pearson Education, Upper saddle River, New Jersey (2002)

30. Tan, T.-S., Goh, T.-L., Yong, K.-Y.: Properties of Singapore marine clays improved by cement mixing. Geotech. Test. J. 25(4), 422-433 (2002). https://doi.org/10.1520/GTJ11295J

31. Mitchell, J.K., Soga, K.: Fundamentals of soil behavior. Wiley, Hoboken (2005)

32. Bogas, J.A., Gomes, M.G., Gomes, A.: Compressive strength evaluation of structural lightweight concrete by non-destructive ultrasonic pulse velocity method. Ultrasonics 53(5), 962-972 (2013)

33. Chang, T.-P., Lin, H.-C., Chang, W.-T., Hsiao, J.-F.: Engineering properties of lightweight aggregate concrete assessed by stress wave propagation methods. Cem. Concr. Compos. 28(1), 57-68 (2006)

34. Khan, Z., Majid, A., Cascante, G., Hutchinson, D.J., Pezeshkpour, P.: Characterization of a cemented sand with the pulse-velocity method. Can. Geotech. J. 43(3), 294-309 (2006)

35. Jansen, D., Goetz-Neunhoeffer, F., Lothenbach, B., Neubauer, J.: The early hydration of Ordinary Portland Cement (OPC): an approach comparing measured heat flow with calculated heat flow from QXRD. Cem. Concr. Res. 42(1), 134-138 (2012)

36. Chew, S., Kamruzzaman, A., Lee, F.: Physicochemical and engineering behavior of cement treated clays. J. Geotech. Geoenviron. Eng. 130(7), 696-706 (2004)

Publisher's Note Springer Nature remains neutral with regard to jurisdictional claims in published maps and institutional affiliations. 